NASZA DERMATOLOGIA Onlin OUR DERMATOLOGY Online

Source of Support Nil

Competing Interests: None

\section{EFFECT OF ANTIRETROVIRAL THERAPY ON SURVIVAL OF HIV/TB-INFECTED PATIENTS IN UKRAINE}

\author{
Mykhailo Andreychyn ${ }^{1}$, Dmytro Zhyvytsia ${ }^{2}$
}

${ }^{I}$ Department Infectious Diseases, Epidemiology and Dermatovenerology of I.YA.

Horbachevsky Ternopil State Medical University, Ukraine

${ }^{2}$ Department of Infectious Diseases Zaporizhia Medical Academy of Postgraduate

Education, Ukraine

Corresponding author: Mariia Shkilna, $\mathrm{MD}, \mathrm{PhD}$

nadiya20743@gmail.com

\begin{abstract}
Introduction: There is little information from Ukraine about the effect of highly active antiretroviral therapy (HAART) on survival of HIV/ TB-infected patients. We evaluated the survival and the effect of HAART on mortality on these patients.

Methods: Prospective cohort study of HIV patients who developed TB from January 2005 to December 2006 in a Zaporizhzhya AIDS Center, and were tracked for 60 months after start HAART. Survival was determined by Kaplan-Meier method and effect of HAART on survival was evaluated using Cox proportional hazards models.

Results: Eighty patients were studied (mean age 34 years, 50\% male, median CD4 count 103 cell/ $\mu \mathrm{L}$ ). In 60 months of HAART 14 patients died. The probability of survival was $82 \%$. In multivariate analysis, patients with a CD4 cell count $<100 \mu \mathrm{L}$ had a 5 -fold higher risk of mortality (HR 5, 2; 95\% CI 1.4-19, 4) and those with extra pulmonary tuberculosis a 2, 2-fold increased risk (HR 2, 2, 95\% CI 1, 1-8, 3). Conclusions: HAART significantly increased probability of survival and reduced the risk of death for HIV/TB-infected patients in Ukraine.
\end{abstract}

Key words: TB; HIV; HAART; survival; Ukraine

\section{Introduction}

The global HIV pandemic has a dramatic impact on the epidemiology of tuberculosis (TB). It has been estimated that global prevalence of active TB was greater than one third of the estimated 36 million patients infected with HIV. The risk of TB is dramatically increased in HIV-infected patients as a result of a higher probability of either primary progression or reactivation of latent infection [1-3]. The HIV and TB epidemics overlap to a great degree in Eastern Europe countries, including Ukraine. In Ukraine tuberculosis is the most frequent major pportunistic infection (OI) and the leading cause of mortality among HIV-infected patients. In developed countries, prior to the introduction of highly active antiretroviral therapy (HAART), a wide range of survival times in people with TB-HIV was reported [47]. Some of these reports showed associations between immunosuppression, history of AIDS and TB location with risk of death $[5,6]$. In the HAART era morbidity and mortality of people living with HIV and AIDS has been reduced significantly, in both industrialized and less developed regions $[8,9]$. Further, in settings of widespread use, HAART appears to have been responsible for a significant reduction in the incidence of TB, even in places with high prevalence of this disease $[10,11]$. There is also increasing evidence about the efficacy or effectiveness of HAART when used together with anti-TB therapy [12].

To date, there have been limited clinical data regarding survival rates among HIV/TB-infected patients and the impact of HAART on clinical outcomes in Ukraine. We therefore, conducted the present study to determine the survival rate among HIV/TB-infected patients who received HAART. This study also aimed to determine possible risk factors that related to death among these patients and the appropriate timing for initiating HAART after TB diagnosis.

\section{Material and Methods}

A prospective cohort study was conducted among HIV-infected patients who were diagnosed with active TB between January 2005 and December 2006.

In study we included HIV-infected patients older than 18 years. TB diagnosis was confirmed by direct (positive ZiehlNielsen in sputum smear) or pathological (typical granuloma in biopsy) examination.

Pulmonary TB was the one with positive sputum or positive culture of sputum or bronchial aspirate, without clinical or radiological evidence of extra-pulmonary extension. 
Extra-pulmonary TB was considered when there was clinical evidence and positive Ziehl-Nielsen in biopsy from at least one extra-pulmonary location, with or without pulmonary TB.

In general anti-TB therapy was standard according to the World Health Organization (WHO). All patients included in the study received antituberculosis medications as directly observed therapy and in accordance with standard Category 1 regimens.

Prophylactic regimens against opportunistic infections were provided in accordance with national Ukrainian guidelines during all time of the study.

The HAART regimens consisted of three-drug therapy using combinations listed by the WHO as approved first-line regimens.

\section{Statistical analysis}

Median (interquartile range, IQR), and frequencies (\%) were used to describe patients' characteristics in each group. The Kaplan-Meier test was used to estimate the probability of death and the median time to death. To compare survival by baseline immunological status, the Kaplan-Meier analysis was further stratified by baseline CD4 count $(<100$, $100-200$, and $>200$ cells $/ \mu \mathrm{L}$ ). The hazard ratio (HR) and its $95 \%$ confidence interval $(\mathrm{CI})$ derived from univariate and multivariate Cox proportional hazards models. All analyses were performed using STATISTICA 6.0 and SPSS 17.0. A P value less than 0.05 was considered statistically significant.

\section{Results}

A total of 80 patients who met the inclusion criteria were identified. Time of follow-up was 60 months. Mean age at initial presentation was 34 years (range 18-54 years). Forty patients $(50 \%)$ were female. The median (IQR) CD4 cell count was $103 \mu \mathrm{L}(63-182)$. Thirty-seven patients (46\%) had an initial CD4 cell count $<100 / \mu \mathrm{L}, 22(28 \%)$ a count of 100 - $200 / \mu \mathrm{L}, 21(26 \%$.) a count of $>200 / \mu \mathrm{L}$ (Tabl. I).

Injection drug use was the most common route $(65 \%)$ of HIV transmission. The number of patients co-infected with the hepatitis $\mathrm{C}$ virus (HCV) was 57 (71\%). Specific HAART regimens included zidovudine-lamivudineefavirenz, administered to $70(88 \%)$ of the patients; stavudine-lamivudine-efavirenz, administered to $10(12 \%)$. The baseline demographic and clinical characteristics are provided in Table I.

The probabilities of survival after start HAART estimated by the Kaplan-Meier method is shown in Figure 1. Survival rates at 1, 2, 3, 4 and 5 years were $95 \%, 92 \%, 86 \%, 86 \%$, and $82 \%$. Among 14 patients who died, 12 patients $(86 \%)$ died during the first 36 months of HAART. Five of the 14 patients who died, had CD 4 counts less than 50 cells $/ \mu \mathrm{L}$. The causes of death were TB (12 cases), primary CNS lymphoma and cryptococal meningitis (one case for each). Among the 5 patients with HIV-related deaths that occurred during the first 12 months of HAART, we identified 4 in whom death could be attributed to IRIS (all case of tuberculosis meningitis).

Univariate analysis revealed that a baseline CD4 cell count $<100 / \mu \mathrm{L}$ was a significant predictor of mortality (HR 5,$6 ; 95 \%$ CI 1,6-20,1,p=0.02) (Tabl. II). Patients who died had a mean pre-ART CD4 cell count of 77 (43-95) $\mu \mathrm{L}$ compared with $130(65-213) \mu \mathrm{L}$ for those who were alive at the conclusion of the study. Also, in univariate analysis, patients with extrapulmonary tuberculosis had an increased mortality risk (HR 2, 4; 95\% CI 1, 2-10, 4, p=0.032).

Figure 2 shows a Kaplan-Meier curve depicting the probability of death over the 5-year period of observation according to CD4 cell count stratum. The log-rank test indicates $(\mathrm{P}<0,01)$ that the probability of death was statistically significantly different among the different CD4 cell count strata, with the lowest survival $(70 \%)$ among patients who initiated ART with a CD4 cell count $<100$ cells/uL.

In multivariate analysis, patients with a CD4 cell count $<100$ $\mu \mathrm{L}$ had a 5 -fold higher risk of mortality (HR 5,2;95\% CI 1.4$19,4, \mathrm{p}<0.05)$ and those with extrapulmonary tuberculosis a 2,2-fold increased risk (HR 2,2, 95\% CI 1,1-8,3, p<0,05) (Tabl. II). Ages, gender, route of HIV transmission were not predictive of mortality.

\begin{tabular}{|l|l|}
\hline Mean age (years) & $34(18-54)$ \\
\hline Male $(\%)$ & 50 \\
\hline Route of HIV transmissionHeterosexual IDU & $28(35 \%) 52(65 \%)$ \\
\hline Pulmonary TB location $(\%)$ & 35 \\
\hline CD4 T-lymphocyte count $($ cells/ $\mu \mathrm{L})$ Median (IQR) & $103(63-182)$ \\
\hline$<100$ & $37(46 \%)$ \\
\hline $100-200$ & $22(28 \%)$ \\
\hline$>200$ & $21(26 \%)$ \\
\hline Table I. Clinical characteristics of HIV/TB-patients \\
\hline
\end{tabular}




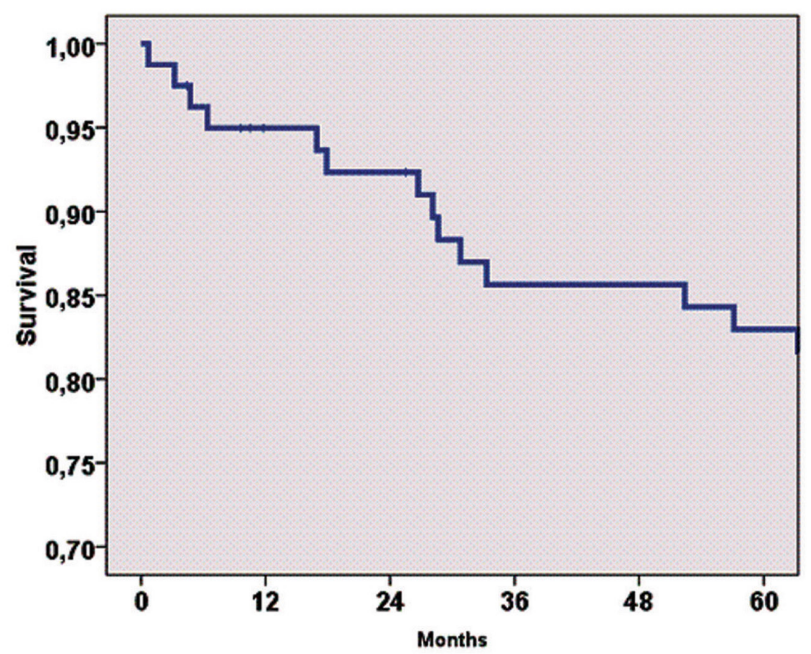

Figure 1. Survival time of HIV/TB- patients by antiretroviral therapy

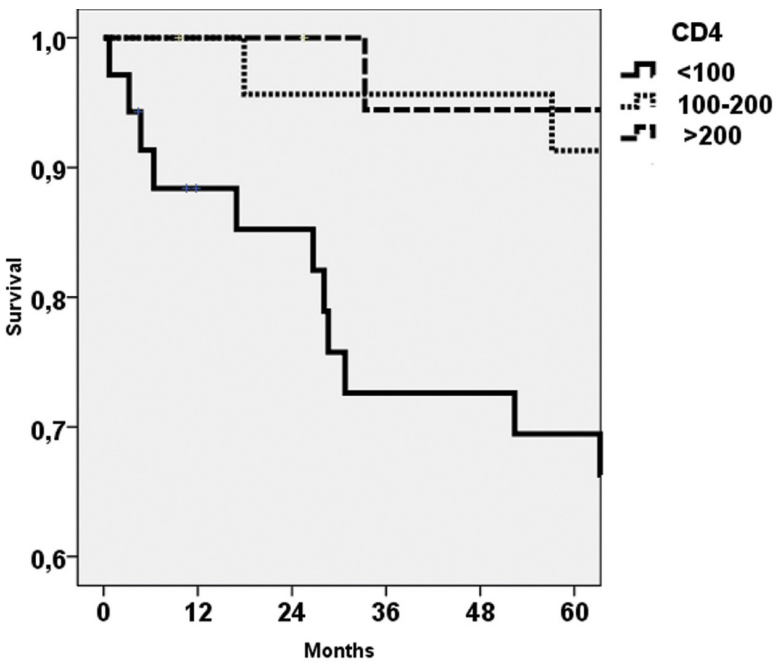

Figure 2. Survival time of HIV/TB- patients by CD4 T-lymphocyte count

\begin{tabular}{|c|c|c|c|}
\hline Variable & Category & $\begin{array}{l}\text { Unadjusted HR } \\
\qquad(95 \% \mathrm{CI})\end{array}$ & $\begin{array}{l}\text { Adjusted HR } \\
\quad(95 \% \text { CI) }\end{array}$ \\
\hline \multirow[t]{2}{*}{ Age } & $>34$ & $1,8(0,6-5,2)$ & $1,4(0,4-4,4)$ \\
\hline & $<34$ & 1 & 1 \\
\hline \multirow[t]{2}{*}{ Gender } & Female & $0,5(0,16-1,6)$ & $0,4(0,13-1,4)$ \\
\hline & Male & 1 & 1 \\
\hline \multirow[t]{2}{*}{ TB location } & Extrapulmonary & $2,4(1,2-10,4)$ & $2,2(1,1-8,3)$ \\
\hline & Pulmonary & 1 & 1 \\
\hline \multirow[t]{2}{*}{ Route of HIV transmission } & IDU & $1,2(0,3-3,2)$ & $1,1(0,4-3,1)$ \\
\hline & non IDU & 1 & 1 \\
\hline \multirow[t]{2}{*}{ CD4 count } & $<100$ cells/uL & $5,6(1,6-20,1)$ & $5,2(1,4-19,4)$ \\
\hline & $>100$ cells/uL & 1 & 1 \\
\hline \multicolumn{4}{|c|}{ Table II. Cox proportional hazards for baseline predictors of HIV/TB- patients } \\
\hline \multicolumn{4}{|c|}{ HR - Cox proportional hazards ratio: $95 \% \mathrm{CI}=95 \%$ confidence interval. } \\
\hline \multicolumn{4}{|c|}{$\begin{array}{l}\text { Unadjusted - Cox proportional hazards ratio comparing group } 1 \mathrm{v} \text {. group } 2 \text { in a univariate model with only one risk factor } \\
\text { included. }\end{array}$} \\
\hline \multicolumn{4}{|c|}{$\begin{array}{l}\text { Adjusted - Cox proportional hazards ratio estimated in a multivariate model including age. Gender, TB location. Route of } \\
\text { HIV transmission, CD4 cell count }\end{array}$} \\
\hline
\end{tabular}

\section{Discussions}

To date, combined ART has been widely used for the treatment for HIV/TB-infected patients in the world. A plenty of studies precisely demonstrate the impact of ART on the survival outcomes among HIV-infected patients with successful immune restoration and reductions in morbidity and mortality [13-15]. However, the data regarding survival rates among HIV/TB-coinfected patients and the impact of HAART on clinical outcomes in Ukraine are still limited.

For HIV/TB-infected patients who did not receive ART, approximately half of them died within 1 year after TB diagnosis. As known, the simultaneous use of HAART with anti-TB therapy in patients with TB-HIV significantly reduces the risk of death in the short and long term compared with the risk of death for those receiving only anti-TB therapy [16-17].

The results from the present study point out that HAART is crucial to improve survival in HIV/TB-infected patients. We observed that degree of immunosuppression (CD4+ $<100$ cells $/ \mu \mathrm{L}$ ) were associated with increased risk of dying and exstapulmonary TB as a risk factor of death. Whalen et al. [8] have shown that survival time was shorter in HIVinfected patients with extrapulmonary TB. This finding may be explained by the fact that patients with extrapulmonary TB have a higher bacterial load of $\mathrm{M}$. tuberculosis and much more severe immunodeficiency status.

Most patients in the present study died of TB-related conditions. The previous studies have demonstrated that death within the first few months of TB treatment may be related to $\mathrm{TB}$, whereas late deaths are attributable to HIV disease progression.

Initiation of HAART and immunological restitution may „unmask» extrapulmonary sites of TB explains the high mortality in first 6 months of HAART. 
We observed 4 deaths that could be attributed to IRIS, of which 3 were attributable to central nervous system syndromes. The IRIS deaths primarily involved the central nervous system, suggesting that central nervous system manifestations may not be as well tolerated as manifestations in other body compartments and may require more-urgent attention.

In conclusion, HAART significantly reduced the risk of death for people with TB-HIV in Ukraine. These findings add further evidence to emphasize the importance of access to HAART, especially in regions where HIV infection and TB disease are highly prevalent.

\section{Contributors}

All authors contributed to conceptualization, design, data collection, and revision of the final draft of the study, which was written by M. Andreichyn and D. Zhyvytsia.

\section{REFERENCES}

1. Corbett EL, Watt CJ, Walker N, Maher D, Williams BG, Raviglione MC, et al. The growing burden of tuberculosis: global trends and interactions with the HIV epidemic. Arch Intern Med. 2003;163:1009-21.

2. Joint United Nations Program on HIV/AIDS (UNAIDS): Report on the global AIDS epidemic. Geneva, Switzerland; 2006.

3. Sharma SK, Mohan A, Kadhiravan T: HIV-TB co-infection: epidemiology, diagnosis \& management. Indian J Med. Res. 2005; 121:550-67.

4. Stoneburner R, Laroche E, Prevots R, Singh T, Blum S, Terry P, et al: Survival in a Cohort of Human Immunodeficiency Virus Infected Tuberculosis Patients in New York City. Arch Intern Med. 1992;152:2033-7.

5. Shafer RW, Bloch AB, Larkin C, Vasudavan V, Seligman $\mathrm{S}$, Dehovitz JD, et al: Predictors of survival in HIV-infected tuberculosis patients. AIDS. 1996;10:269-72.

6. Whalen C, Horsburgh CR, Hom D, Lahart C, Simberkoff M, Ellner J: Site of disease opportunistic infection predict survival in HIV-associated tuberculosis. AIDS. 1997;11:455-60.
7. Munsiff SS, Alpert PL, Gourevitch MN, Chang CJ, Klein RS: A prospective study of tuberculosis and HIV disease progression. J AIDS and Human Retrovirology. 1998;19:361-6.

8. Mocroft A, Vella S, Benfeld TL, Chiesi A, Miller V, Gargalianos $\mathrm{P}$, et al. Changing patterns of mortality across Europe in patients infected with HIV-1. Lancet. 1998;352:1725-30.

9. Teixeira PR, Vitoria MA, Barcarola J: Antiretroviral treatment in resource-poor settings: the Brazilian experience. AIDS. 2004;18(Supple 3):S5-S7.

10. Jones JL, Hanson DL, Dworkin MS, DeCock KM: HIVassociated tuberculosis in the era of highly active antiretroviral therapy. Int J Tuber Lung Dis. 2000;4:1026-31.

11. Badri M, Wilson D, Wood R: Effect of highly active antiretroviral therapy on incidence of tuberculosis in South Africa: a cohort study. Lancet. 2002;359:2059-64.

12. Patel A, Patel K, Patel J, Shah N, Patel B, Rani S: Safety and antiretroviral effectiveness of concomitant use of rifampicin and efavirenz for antiretroviral-naive patients in India who are coinfected with tuberculosis and HIV-1. J Acquire Immune Defect Syndr. 2004;37:1166-9.

13. Wong KH, Chan KC, Lee SS: Delayed progression to death and to AIDS in a Hong Kong cohort of patients with advanced HIV type 1 disease during the era of highly active antiretroviral therapy. Clin Infect Dis. 2004;39:853-60.

14. Hogg RS, Heath KV, Yip B, Craib KJ, O'Shaughnessy MV, Schechter MT, et al. Improved survival among HIV-infected individuals following initiation of antiretroviral therapy. JAMA. 1998;279:450-4.

15. Palella FJ Jr, Delaney KM, Moorman AC, Loveless MO, Fuhrer J, Satten GA, et al. Declining morbidity and mortality among patients with advanced human immunodeficiency virus infection. HIV Outpatient Study Investigators. N Engl. J Med. 1998;338:85360 .

16. Girardi E, Palmieri F, Cingolani A, Ammassari A, Petrosillo N, Gillini L, et al. Changing clinical presentation and survival in HIVassociated tuberculosis after highly active antiretroviral therapy. J Acquire Immune Defect Syndr. 2001;26:326-31.

17. Dheda K, Lampe FC, Johnson MA, Lipman MC: Outcome of HIV-associated tuberculosis in the era of highly active antiretroviral therapy. J Infect Dis. 2004;190:1670-6.

\footnotetext{
Copyright by Mykhailo Andreychyn, et al. This is an open access article distributed under the terms of the Creative Commons Attribution License,
} which permits unrestricted use, distribution, and reproduction in any medium, provided the original author and source are credited. 